\title{
COMUNICAÇÃO ALTERNATIVA: DISCUTINDO A PRÁTICA PEDAGÓGICA E A UTILIZAÇÃO DESSES RECURSOS
}

\author{
BUREI, Ana Paula1 \\ RODRIGUES, Roseli Viola2 \\ STANGHERÇIN, Domingos Carlos3
}

\section{RESUMO}

O artigo tem intenção de apresentar um estudo sobre "A Comunicação Alternativa: discutindo a prática pedagógica e a utilização desses recursos". O local da pesquisa foi uma Instituição de ensino de Educação Infantil e Ensino Fundamental na Modalidade de Educação Especial. A escolha desse tema justifica-se pela preocupação em investigar como é feita a intervenção pedagógica aos alunos nesse espaço, para isso foram realizadas observações. O lócus do estudo trouxe como resultado que a aprendizagem em sala de aula depende de metodologias e recursos específicos e adaptados ao próprio sujeito que aprende, considerando suas especificidades individuais.

Palavra-chave: Comunicação alternativa; Prática Pedagógica; Tecnologia Assistiva.

\section{COMMUNICATION ALTERNATIVE: COMMUNICATION ALTERNATIVE: DISCUSSING THE PRACTICE AND EDUCATIONAL USE OF THESE RESOURCES}

\begin{abstract}
The article intends to present a study on "Alternative communication: discussing thepedagogical practice and the use of these resources". The location of the research was an institution of learning in early childhood education and elementary educationin special education. The choice of this theme is justified by the concern to investigate how educational intervention is made to students in this space, for that were conducted observations. The locus of the study brought as a result that learning in the classroom depends on specific features and methodologies and adapted to their own subject learning, considering their individual specificities.
\end{abstract}

Keyword: Alternative Communication; Teaching Practice; Assistive Technology.

\footnotetext{
${ }^{1}$ Universidade Estadual do Centro Oeste - UNICENTRO,

${ }^{2}$ Universidade Estadual do Centro-Oeste - UNICENTRO,

${ }^{3}$ Uniasselvi.

UNESC

Criar Educação, Criciúma, v. 6, nº1, julho/novembro 2016.- PPGE -
} 


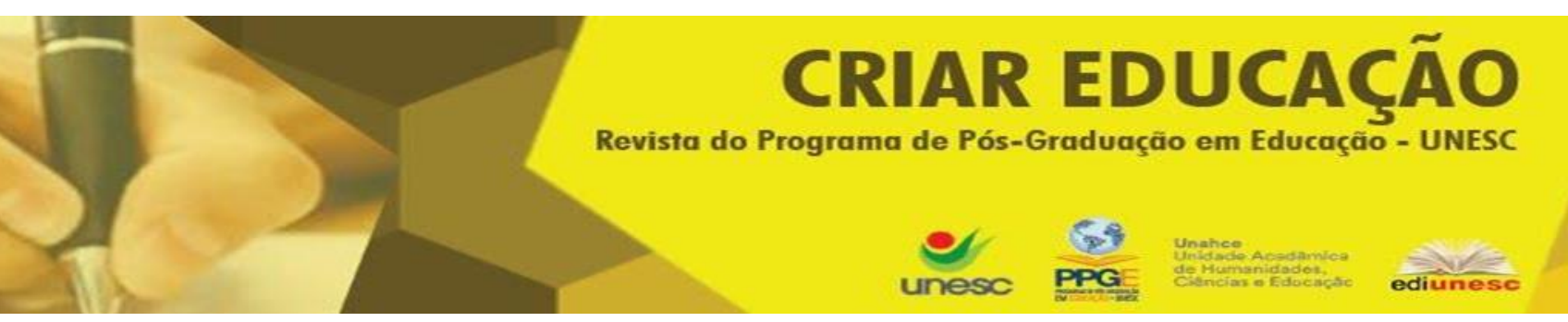

INTRODUÇÃO

O presente estudo denominado "Comunicação alternativa: Discutindo a prática pedagógica e a utilização desses recursos"tem como proposta investigar sobre a Comunicação Alternativa teve origem em compreender quais metodologias e recursos didático-pedagógico que o professor utiliza em sala de aula como instrumentos de mediação para a aprendizagem dos alunos que apresentam Necessidades Educacionais Especiais (N.E.E).

Este estudo tem como base pesquisa bibliográfica e pesquisa de campo, abordando num primeiro momento o Conceito de Deficiência e a Comunicação Alternativa como metodologia e na sequência apresenta a análise dos dados, os quais foram obtidos por meio de observação e entrevista.

\section{CONCEITUANDO DEFICIÊNCIA}

A história mostra que os deficientes, passaram anos sendo tachados como criaturas demoníacas, sendo vistos como pessoas que pudessem fazer mal. Mas sabemos que não é bem assim. Pois nem todos sabem definir o que é uma pessoa deficiente. Pensando assim, Ribas (1994) nos diz que houve um tempo, por volta da década de 1970, em que as definições dadas antes pelas pessoas, como "ceguinho, louco", etc., não davam mais conta de definir o deficiente. Assim, para a declaração dos Direitos das Pessoas deficientes,

[...] aprovada pela Assembleia Geral da ONU, em 9 de dezembro de 1975, que proclama em seu artigo I:O termo 'pessoas deficientes' refere-se a qualquer pessoa incapaz de assegurar por si mesma, total ou parcialmente, as necessidades de uma vida individual ou social normal. Em decorrência

Criar Educação, Criciúma, v. 6, ํ2, julho/novembro 2017.- PPGE - UNESC 


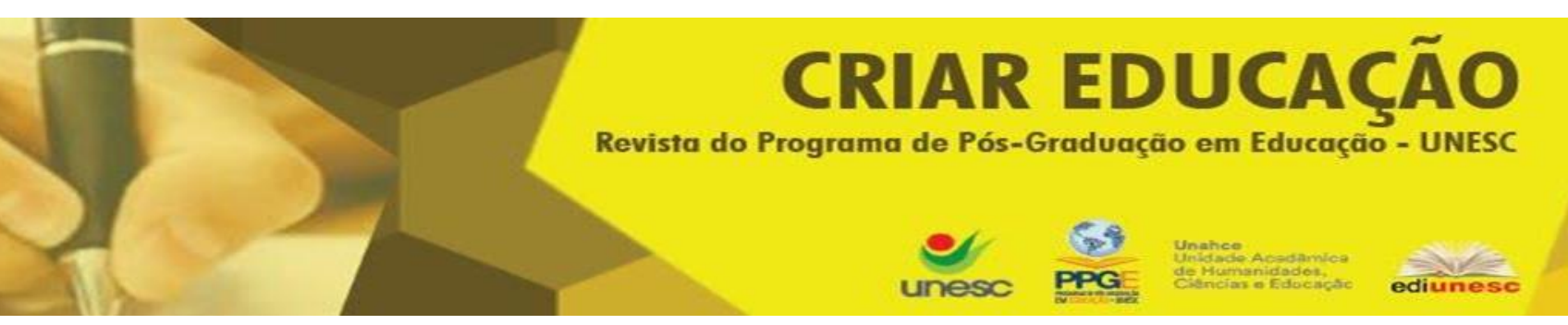

de uma deficiência congênita ou não, em suas capacidades físicas ou mentais (RIBAS, 1994, p.9).

Ribas (1994) expõe que "muitos de nós somos portadores de algum tipo de lesão, são míopes, diabéticos, hipertensos, têm altura ou peso não considerados adequados, possuem algum tipo de disfunção orgânica" (RIBAS, 1994, p. 11). Assim, entendemos que deficientes não são apenas aquelas pessoas que possuem uma deficiência congênita, ou as adquiridas, mas deficientes, somos todos, pois, em qualquer momento de nossa vida, podemos estar deficientes, podemos estar com um braço quebrado, podemos estar passando por problemas psicológicos, podemos não ter uma altura ou um peso considerado normal. E em cada um desse momento precisamos nos superar, e também precisamos de ajuda e de respeito dos demais, afinal, sem isso, não podemos chegar muito longe.

"A palavra 'deficiente' tem um significado muito forte. De certo modo ela se opõe a palavra 'eficiente'. Ser 'deficiente', antes de tudo, é não ser 'capaz', não ser 'eficaz"' (RIBAS, 1994, p. 12). A palavra e sua definição não podem interferir em nossa maneira de ver e julgar a pessoa deficiente, pois ela pode ser, ou estar deficiente, mas isso não implica que ela é uma pessoa incapaz.

Assim, podemos ver a importância que tem em haver profissionais qualificados para trabalhar com os deficientes. E também da importância que tem em existir métodos diferenciados para se trabalhar com o deficiente, de acordo com a sua deficiência, ou melhor, com a sua dificuldade.

\section{COMUNICAÇÃO ALTERNATIVA}

Ao explicar a comunicação, Manzini \&Deliberato (2006) ressaltam, que geralmente, conceituamos a palavra dizendo que nos comunicamos por meio da fala e que é por meio dela que expressamos nossas emoções, e conhecemos pessoas e

Criar Educação, Criciúma, v. 6, ํ2, julho/novembro 2017.- PPGE - UNESC 


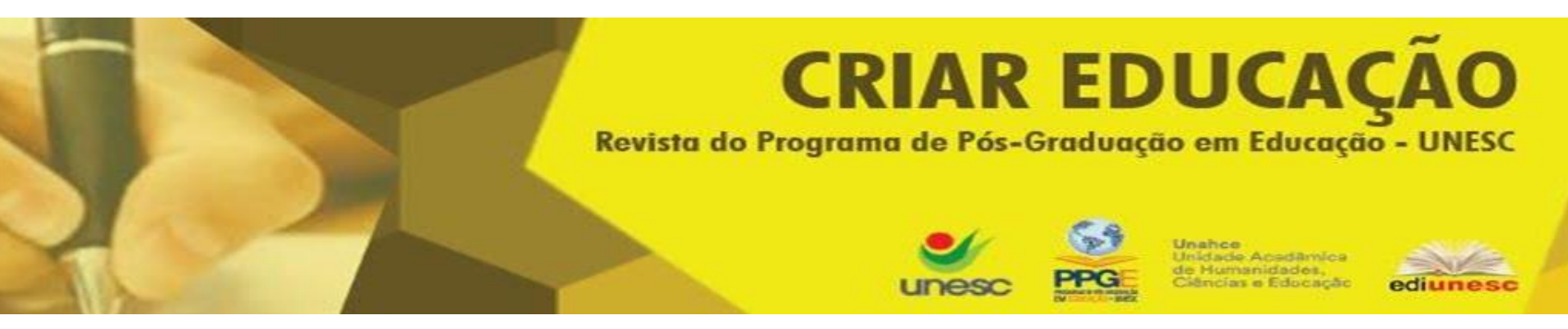

nos deixamos conhecer. E complementam dizendo que ao falarmos nós podemos sorrir, demonstrar em forma de gestos para complementar o que falamos, balançar a cabeça, e que uma forma de comunicação importante entre duas pessoas é a expressão facial, pois a nossa expressão diz tudo, o que se passa, se estamos bem ou não, se não estamos com vontade de sorrir e entre tantas coisas.

Além da expressão facial, temos os gestos que são muito importantes para a comunicação, onde podemos indicar uma pessoa, dizer "tchau" ou até um "oi" apenas com um gesto. Assim, Manzini \&Deliberato (2006) mostram que a comunicação é muito importante e que ela não se faz apenas da fala, mas sim do nosso corpo todo.

O professor pergunta-se: "Parece que ele entende tudo, mas não fala e não consegue escrever. Como poderei saber o que ele quer, gosta, aprendeu, ou quais são suas dúvidas? Existe alguma forma alternativa de ele comunicar o que deseja?" (BERSCH, 2007, p. 32).

O trabalho com a criança deficiente requer recursos que permitam 0 acesso aos conhecimentos trabalhados. Recorremos, então, à Tecnologia Assistiva (T.A), que é definida como

[...] uma expressão utilizada para identificar todo o arsenal de recursos e serviços que contribuem para proporcionar ou ampliar habilidades funcionais de pessoas com deficiência e, consequentemente, promover vida independente e inclusão (BERSCH, 2007, p. 31).

Manzini (2005) explica a T.A como recursos que estão muito próximos do nosso dia a dia, como a bengala dos nossos avós, um aparelho de surdez e até mesmo um carro adaptado. Desta forma, complementa os exemplos dizendo que "tecnologia assistiva pode ser compreendida como recursos, equipamentos ou aparatos que auxiliam, funcionalmente, no desempenho de alguma atividade" (MANZINI, 2005, p. 83).

Criar Educação, Criciúma, v. 6, ำ2, julho/novembro 2017.- PPGE - UNESC 


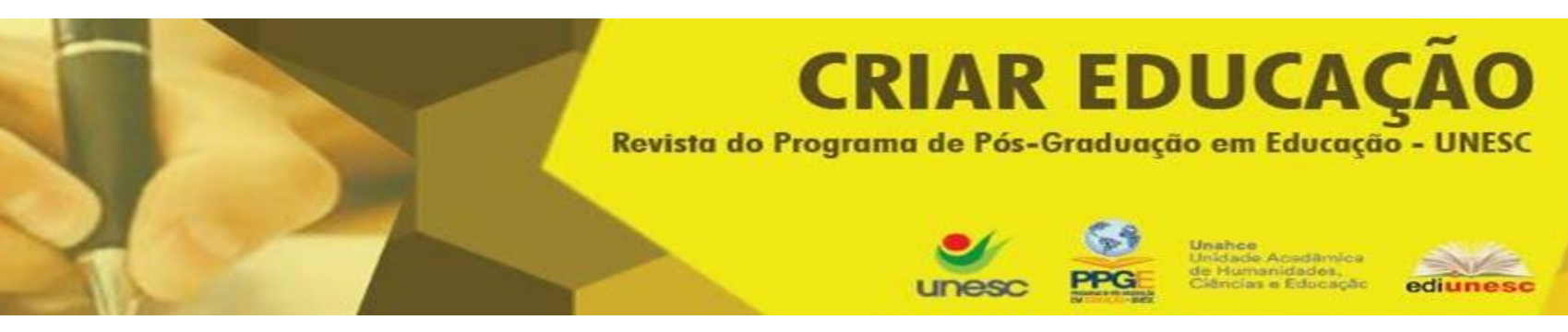

Avila (2013) apresenta a definição do Comitê de Ajudas Técnicas da Coordenadoria Nacional para Integração da Pessoa Portadora de Deficiência "como uma área do conhecimento de caráter interdisciplinar, que engloba produtos, recursos, metodologias, estratégias, práticas e serviços visando promover a inclusão social de Pessoas Portadoras de Deficiência (PNEs)" (AVILA, 2013, p.117).

Os recursos utilizados, ferramentas ou métodos, se constituirão em mediadores do processo de aprendizagem. "Mediação, em termos genéticos, é o processo de intervenção de um elemento intermediário numa relação; a relação deixa, então, de ser direta e passa a ser mediada por esse elemento" (OLIVEIRA, 1993, p. 26).

Bersch (2007) classifica a T.A. através de algumas modalidades, que podem variar conforme a instituição e os autores que a trabalham. Dentre essas modalidades que a autora coloca, podemos citar algumas, como: Auxílio para a vida diária e vida prática; recursos de acessibilidade ao computador, recursos para cegos ou para pessoas com visão subnormal; adaptações em veículos e a Comunicação Aumentativa e Alternativa, que é o foco da nossa pesquisa, que é um recurso pedagógico que possibilita a aprendizagem do aluno deficiente, que tem dificuldade de comunicação, ou seja, problemas na fala a na sua escrita.

A Comunicação Aumentativa e Alternativa - CAA é uma das áreas da TA que atende pessoas sem fala ou escrita funcional ou em defasagem entre sua necessidade comunicativa e sua habilidade em falar e/ou escrever. Busca então, através da valorização de todas as formas expressivas do sujeito e da construção de recursos próprios desta metodologia, construir e ampliar sua via de expressão e compreensão. Recursos como as pranchas de comunicação, construídas com simbologia gráfica (desenhos representativos de idéias), letras ou palavras escritas, são utilizados pelo usuário da CAA para expressar suas questões, desejos, sentimentos, entendimentos. A alta tecnologia nos permite também a utilização de vocalizadores (pranchas com produção de voz) ou do computador, com softwares específicos, garantindo grande eficiência na função comunicativa. Desta forma, o aluno com deficiência, ao fazer uso da linguagem, passa de

Criar Educação, Criciúma, v. 6, ํo2, julho/novembro 2017.- PPGE - UNESC 


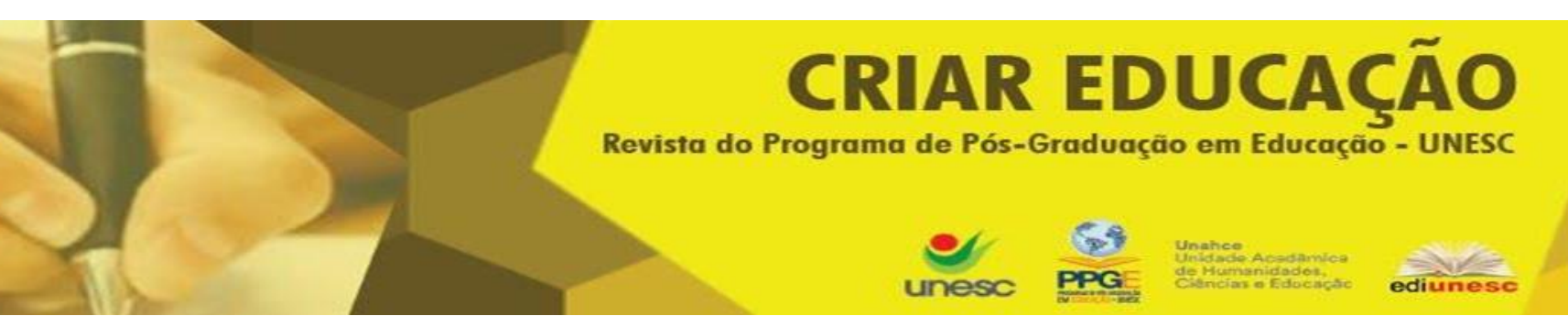

uma situação de passividade para outra, a de ator ou de sujeito do seu processo de desenvolvimento (BERSCH \& SCHIRMER, 2005, p. 90).

A C.A.A. tem relevância para a pessoa que tem dificuldades de comunicar-se, pois ela pode compensar a fala, como no caso da aumentativa e pode substituir a fala e a comunicação no caso da alternativa. A designação Aumentativa é explicada por Avila (2013), a qual fala que a palavra pode variar de autor para autor, onde uns podem colocar como: suplementar, ampliada, facilitadora. Mas o seu sentido sempre será o mesmo.

Avila (2013), para definir a C.A (Comunicação Alternativa), traz a definição de American Speech-Language-HearingAssociation onde apresenta a C.A "como um conjunto de técnicas para o desenvolvimento da oralidade e do letramento em sujeitos que apresentam déficits de linguagem" (2013, p. 117).

A C.A é também apresentada por Manzini \&Deliberato que apresentam

como

[...] um conjunto de procedimentos técnicos e metodológicos direcionado a pessoas acometidas por alguma doença, deficiência, ou alguma outra situação momentânea que impede a comunicação com as demais pessoas por meio dos recursos usualmente utilizados, mais especificamente a fala. (2006, p. 4)

Bersch\&Schirmer (2007), evidenciam que, antigamente, dispensava-se a comunicação auxiliar, pois as pessoas acreditavam que esse auxílio não era necessária e que aquele deficiente mais tarde poderia falar. Pensava-se ainda que se houvesse uma forma alternativa, essa pessoa perderia as possibilidades de aprender a falar. Mas sabemos que é exatamente ao contrário.

Há vários motivos pelos quais a comunicação auxiliada pode realmente melhorar as chances de uma pessoa desenvolver as habilidades de fala. Quando a fala é experimentada ou trabalhada isoladamente geralmente

Criar Educação, Criciúma, v. 6, n², julho/novembro 2017.- PPGE - UNESC 


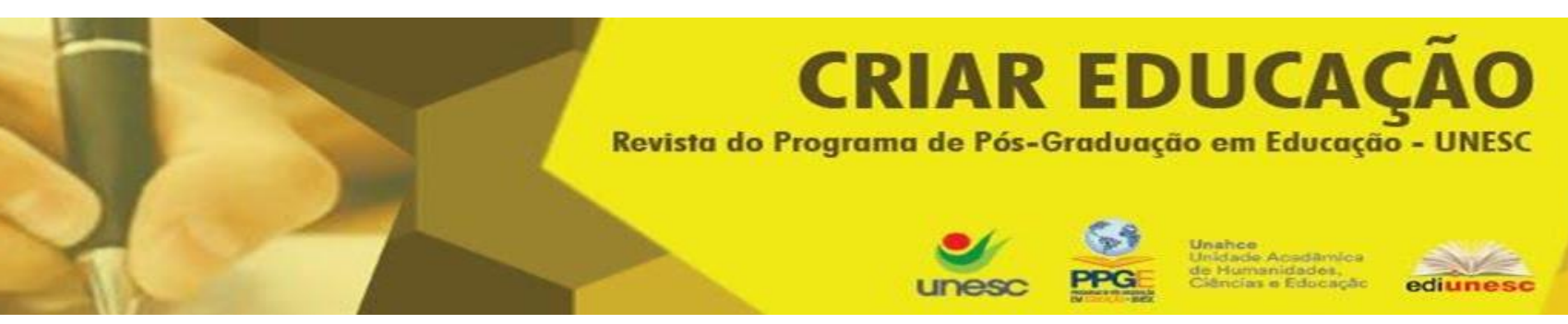

produz tensão. Para muitos indivíduos essa tensão diminui as chances de fala compreensível, e o resultado é o aumento da sua frustração. Quando o indivíduo é encorajado a verbalizar cada palavra ou frase, apontando para seu recurso de comunicação, sua fala torna-se mais relaxada e por isso, melhor sucedida. (JOHNSON, 1998, p. 2)

Falando sobre a importância que tem a C.A. na vida das pessoas com dificuldade de comunicação, Manzini \&Deliberato (2006), alientam que os métodos alternativos na relação/interação do professore com o aluno com necessidades especiais são de extrema importância, pois faz com que o aluno seja incluso. Assim, o aluno que não possa falar, poderá interagir com seus colegas e professor, podendo expor suas ideias, pensamentos e sentimentos, usando as metodologias adaptadas para o meio qual está inserido.

A C.A, segundo Bersch\&Schirmer (2007), está destinada às pessoas de todas as idades que não têm fala nem escrita funcional, devido a uma deficiência mental, autismo, acidente vascular cerebral, traumatismo cranioencefálico, paralisia cerebral, etc.

A introdução da CAA deve acontecer sempre que houver um distanciamento entre a capacidade compreensiva e expressiva de um sujeito ou quando a possibilidade de se fazer entender é menor do que a de seus pares (pessoas da mesma idade), diminuindo assim as oportunidades de interação e relacionamento deste indivíduo. (BERSCH \& SCHIRMER, 2007, p.60)

Ainda segundo Bersch\&Schirmer (2007), na C.A.A. existe o SCAA (Sistema de Comunicação Aumentativa e Alternativa), o qual são recursos, técnicas, e estratégias que ajudam e até mesmo substituem uma comunicação. Esses recursos podem ser organizados por recursos "que não necessitam de auxílio externo (sinais manuais, gestos, apontar, piscar os olhos, sorrir, vocalizar) e os que necessitam de auxílio externo (objeto real, miniatura, retrato, símbolo gráfico, letras e palavras, dispostos em recursos de baixa tecnologia)." (BERSCH \& SCHIRMER, 2007, p.60)

Criar Educação, Criciúma, v. 6, n², julho/novembro 2017.- PPGE - UNESC 


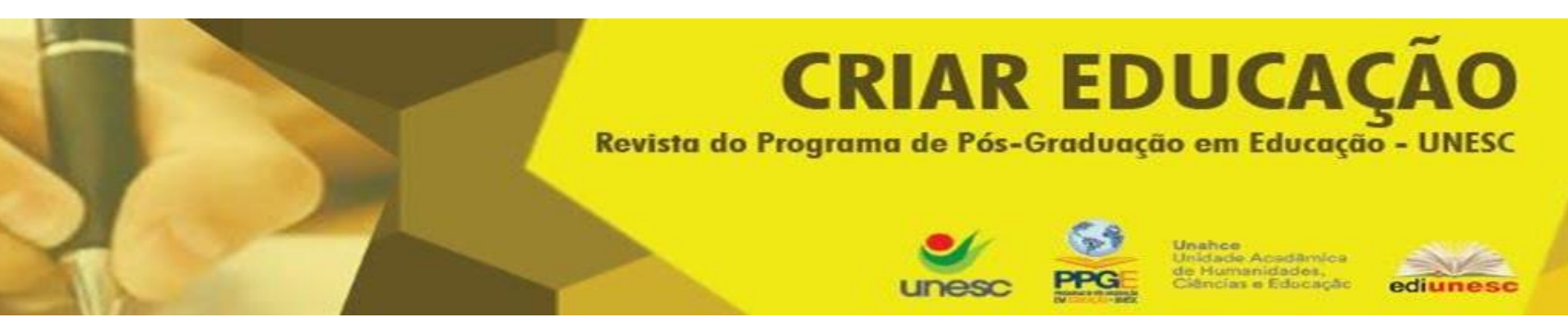

Com esses recursos, o usuário de C.A poderá se comunicar, expressar suas ideias, pois poderá usar o seu corpo para tal ou usar os recursos com "auxílio externo" (BERSCH \& SCHIRMER, 2007, p.60), onde se utilizará de pranchas de comunicação, também citadas por Avila (2013), "fichas, cartões, pastas, carteiras e livros traduzidos em sistema simbólico e ainda os vocalizadores e computadores com pranchas dinâmicas. Distinguimos recursos de alta e baixa tecnologia, sendo os últimos capazes de produzir voz" (BERSCH \& SCHIRMER, 2005, p.90).

Além de Bersch\&Schirmer (2007) e Avila (2013), temos Manzini \&Deliberato (2006) que falam também sobre os sistemas de baixa tecnologia, como fotos, figuras desenhos, letras, palavras. E também falam sobre a alta tecnologia que são os sistemas de computadores como os Softwares.

Os recursos de baixa tecnologia são apontados e descritos por Bersch\&Schirmer (2007), como os objetos reais, nos quais o aluno apontará o que quer, como roupa para vestir, material escolar; a miniatura, onde apresentam-se relevos de figuras para o aluno, para que assim este possa reconhecer e confirmar a mensagem que quer transmitir; os objetos parciais, em que se usam-se objetos menores para representar um maior, como o CD para o computador; a fotografia, que pode ser usada em uma prancha de comunicação com figuras recortadas, para representar, pessoas, sentimentos, etc.; os símbolos gráficos, que são construídos pranchas e cartões de comunicação.

Estes recursos podem ter como complemento um piscar de olhos, um apontar, gestos, sorrisos. Como muito bem exemplificam Bersch\&Schirmer (2007), o deficiente, ao se comunicar, apontará para um recurso externo, isso são placas, prancha de símbolos, etc., assim, ao apontar ele imitirá seus recursos pessoais, seus sons, sorrisos, etc.Para definir melhor a C.A, Manzini \&Deliberato (2006) dividem-na em Comunicação Apoiada e Comunicação Não apoiada.

Criar Educação, Criciúma, v. 6, ํo2, julho/novembro 2017.- PPGE - UNESC 


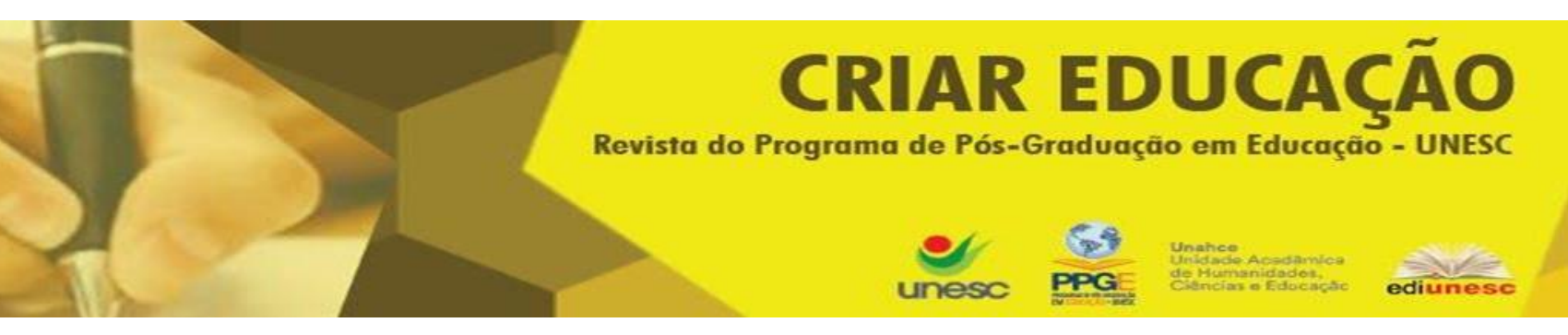

A comunicação apoiada englobaria todas as formas de comunicação que possuem expressão lingüística na forma física e fora do corpo do usuário, como objetos reais, miniaturas de objetos, pranchas de comunicação com fotografias, fotos e outros símbolos gráficos e, ainda, os sistemas computadorizados. (2006, p.5).

Manzini \&Deliberato (2006) falam que na Comunicação apoiada há aqueles alunos que irão à depender de alguém para que use a forma de comunicação. Ele precisará da pessoa para manusear os materiais para que haja a comunicação. Ainda salientam que há aquele aluno que consegue se expressar pelo olhar, ou até aponta para o material com a língua, mas não consegue virar uma página de um livro, ou apontar para a figura desejada. Nestes casos precisa de uma pessoa que facilite essa comunicação.

"A comunicação não apoiada englobaria as expressões próprias daquela pessoa, tais como os sinais manuais, expressões faciais, língua de sinais, movimentos corporais, gestos, piscar de olhos para indicar "sim" ou "não"' (MANZINI \& DELIBETRATO, 2006, p. 5). Essas expressões são próprias da pessoa, são realizados por ela, sem precisar de uma pessoa para auxiliar.

Bersch\&Schirmer (2007) trazem os PCS (Símbolos de Comunicação Pictórica), que foram pensados em 1980, por Roxanna Mayer Johnson. "Os Símbolos de Comunicação Pictórica (PCS), são primariamente compostos de desenhos de linha simples" (JOHNSON, 1998, p.5). Estes símbolos são basicamente utilizados por pessoas de qualquer idade e "são de fácil reconhecimento e, por isso, muito utilizados por crianças ou indivíduos que apresentam dificuldades em conhecer representações mais abstratas."(BERSCH \& SCHIRMER, 2007, p.62)

Para Johnson (1998, p.3) "O uso de um recurso de baixa tecnologia deve ser sempre considerado, mesmo que o indivíduo disponha de outros meios de comunicação". O autor exemplifica isso, dizendo que o indivíduo deve ser incentivado a usar, por exemplo, a língua de sinais, os gestos, a fala, tecnologia alta

Criar Educação, Criciúma, v. 6, ํo2, julho/novembro 2017.- PPGE - UNESC 


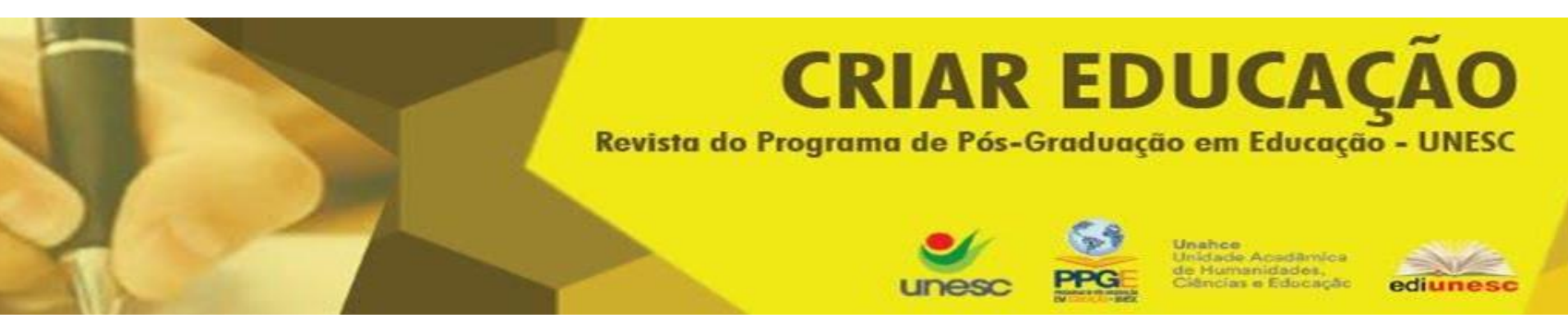

ou baixa, pois todos esses recursos juntos facilitarão à a comunicação. Ainda para mostrar que a tecnologia baixa deve ser muito usada, exemplifica fatos nos quais 0 indivíduo pode responder a sua mãe com um sorriso e ela com certeza irá entender, mas em um restaurante, terá que ter uma prancha de comunicação para poder fazer o seu pedido e se comunicar com as pessoas.

De acordo com Bersch\&Schirmer (2007, p.63) "Em uma prancha de comunicação são colocados vários símbolos gráficos que representam mensagens. O vocabulário de símbolos deverá ser escolhido de acordo com as necessidades comunicativas de seu usuário". Essas pranchas possibilitam que a pessoa expresse os seus sentimentos, seus gostos, seus desejos.

As autoras Bersch\&Schirmer (2007), mostram formas de confeccionar e trabalhar com a C.A usando a baixa tecnologia. Dão exemplos como cartões de comunicação, que são muito utilizados com crianças que estão iniciando a C.A.A, para assim depois ir para as pranchas; Mesas com símbolos não fixados; Avental, usado por professores ou pais das crianças; Pastas de comunicação (espécie de um fichário); Porta documentos/cartões, que são fáceis para o transporte, por exemplo, em uma aula de educação física; Álbum de fotografias; Agenda e calendários; Livros construídos pelos próprios alunos, com simbologias C.A; Livros adaptados com a simbologia da C.A; Jogos construídos com a C.A; Simbologia da C.A nas atividades educacionais (tapete das sensações, estudo das partes do corpo, redação sobre passeio, etc.).

O início das atividades com a C.A. deve acontecer, conformeBersch\&Schirmer (2007) o quanto antes, ao se observar um atraso no desenvolvimento da fala e da escrita, tendo como comparação outra criança com a mesma faixa etária. Para iniciar o trabalho com a CA é preciso fazer uma "investigação" sobre o aluno e sobre o meio social o qual está inserido para que o profissional possa saber qual é a melhor forma e a estratégia mais adequada para

Criar Educação, Criciúma, v. 6, nº2, julho/novembro 2017.- PPGE - UNESC 


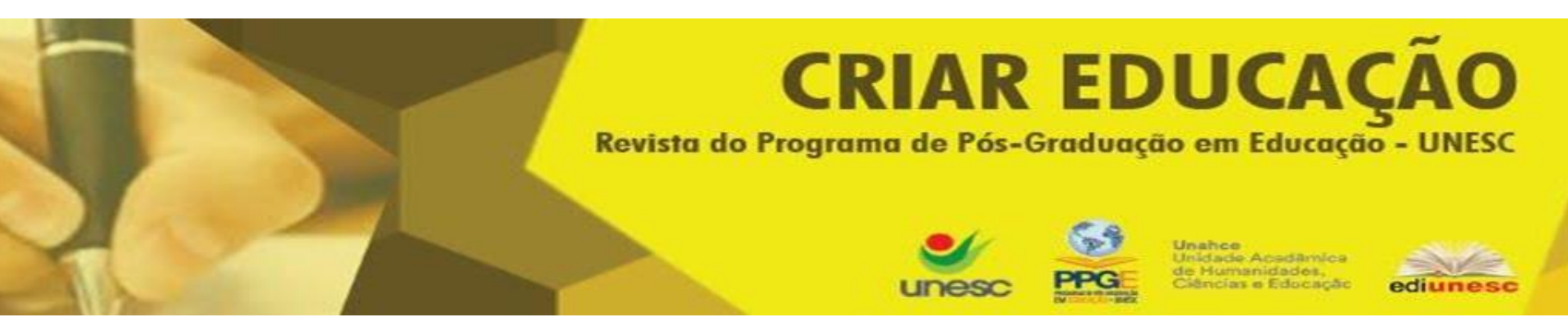

usar a C.A. Segundo Manzini \&Deliberato (2006, p.8), "cada necessidade é única e, portanto, cada caso deve ser estudado com muita atenção". Esse trabalho com a C.A não deve ser descontextualizado, muito pelo contrário, o profissional deve sempre procurar trazer essa metodologia para o meio em que o aluno está inserido, para que assim, esse início de interação seja mais aproveitado, pois o objetivo das pranchas de comunicação, por exemplo, é o de comunicar e não apenas meras imagens.

Segundo Bersch\&Schirmer (2007) "Existe uma sequência de aquisição que facilita a introdução da C.A.A.: objetos concretos, miniaturas, fotografias, símbolos, palavras/letras" (2007, p.75).

Para a introdução, iniciando com o objeto, Manzini \&Deliberato (2006), dizem que essa é a forma mais concreta possível, pois é real, e para ser mais real ainda, a sua representação pode ser feita com um objeto que se assemelham real (ex: vemos muitas frutas, que são tão bem trabalhadas que se confundem com o real; animais). Assim, também pode ser trabalhado com as miniaturas, tudo o mais real possível.

Sobre o uso de fotografias e figuras, Manzini \&Deliberato (2006) dizem que o seu uso é recomendado apenas quando o aluno reconhece a foto ou a figura e a relaciona com o objeto real, já trabalhado.

Bersch\&Schirmer (2007) e Manzini \&Deliberato (2006) destacam que para uma boa introdução da C.A, é preciso que todas as pessoas envolvidas com a criança estejam interessadas no conhecimento do recurso. E essas pessoas devem estar atentas para ver se esses recursos são adaptados para possibilitar que a mensagem seja transmitida.

Manzini e Deliberato (2006) dizem que, ao confeccionar um material como pranchas, fichários, pastas, etc., é preciso verificar o tamanho que é mais adequado para cada aluno, pois para um aluno o tamanho pode estar bom, mas

Criar Educação, Criciúma, v. 6, no2, julho/novembro 2017.- PPGE - UNESC 


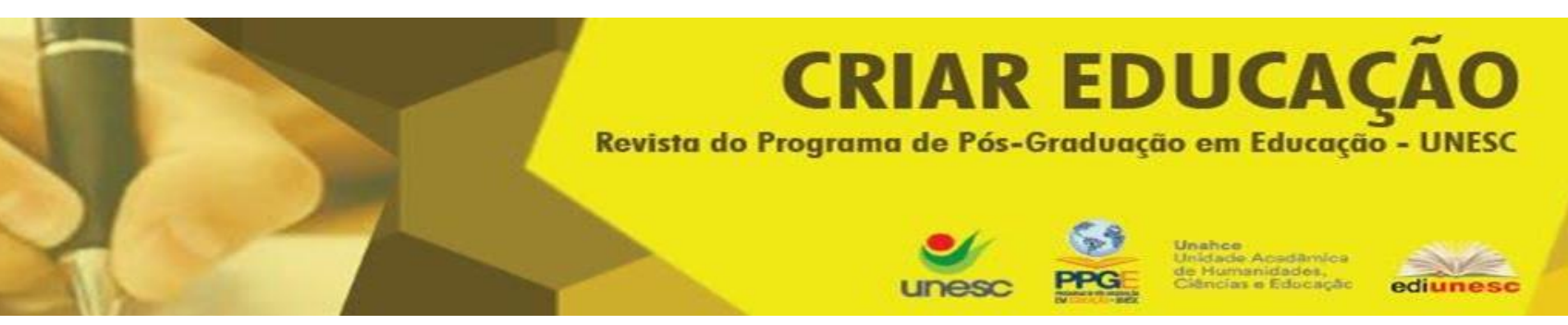

para o outro pode ser muito pequeno. Assim, percebemos que como os autores explicitaram cada sujeito é único e, desta forma, é preciso adequar todos os materiais.

Ao confeccionar as pranchas de comunicação, é preciso identificar o local em que o usuário da C.A irá se comunicar, assim tornando mais fácil o seu manuseio. Desta forma, o mais indicado são as pranchas temáticas, que terão o que for preciso no momento, como por exemplo, a hora do recreio.

Bersch\&Schirmer (2007) nos fazem parar para pensar sobre a possibilidade de um aluno que precise dos recursos da C.A, mas não tem os movimentos das partes do corpo para apontar as pranchas, assim, nos mostram a técnica de varredura onde o aluno deficiente terá um ajudante que apontará para a prancha, de uma em uma figura, e quando apontar a desejada o aluno irá emitir um som indicando seu desejo.

Assim, como Bersch\&Schirmer (2007), Johnson (1998) diz que

\begin{abstract}
A técnica da varredura exige somente que a pessoa tenha uma resposta controlável consistente, como sacudir a cabeça, bater um pé ou fazer um movimento de cabeça ou olhos. Os recursos de tecnologia simples necessitam um facilitador para apontar para os símbolos de maneira sistemática enquanto o usuário sinalizará quando o símbolo desejado for apontado. Alguns recursos de alta tecnologia apresentam varredura automática, dispensando o auxílio de um facilitador. (JOHNSON, 1998, p.15).
\end{abstract}

A técnica de varredura, assim descrita por Manzini \&Deliberato (2006), é considerada como uma "possibilidade de o professor ou outra pessoa ir indicando as figuras das linhas até o aluno escolher por meio do olhar (piscar) ou mesmo de um sorriso. A varredura poderá ser feita pela linha e/ou coluna de figuras e/ou objetos da pasta e/ou das pranchas."(2006, p.36)

Os recursos de alta tecnologia são instrumentos que nem todas as escolas têm e nem todos os alunos deficientes têem em casa também, esses instrumentos são: Vocalizadores - que são pranchas de comunicação que possuem

Criar Educação, Criciúma, v. 6, n², julho/novembro 2017.- PPGE - UNESC 


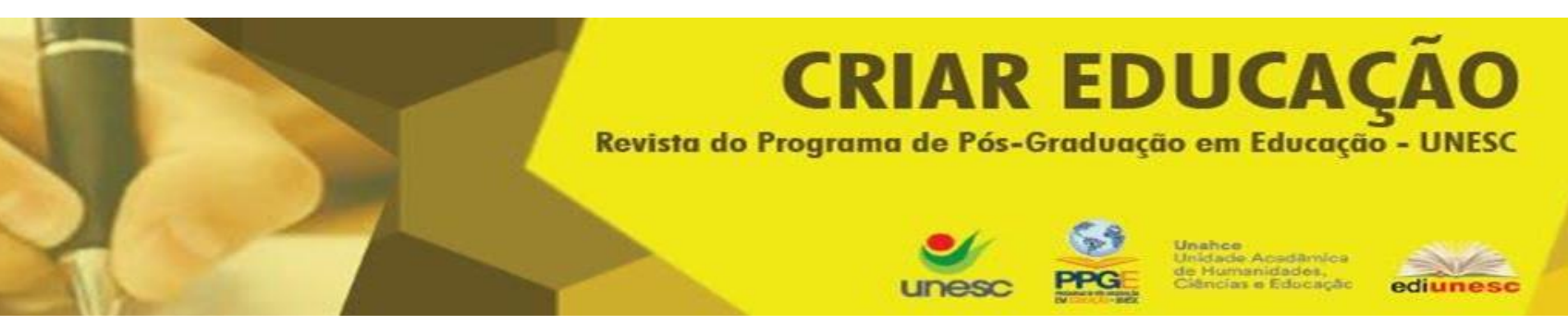

voz. A escolha da mensagem pode ser direta, que é aquela na qual o aluno apontará com uma parte do corpo para a prancha, ou indireta quando é acionada uma luz na prancha que passará de fileira por fileira, para que o aluno possa emitir um sinal identificando a fila para depois identificar a mensagem; Computadores - podem ser usados como recursos de comunicação. Para que isso aconteça, são usados softwares com pranchas dinâmicas, teclados virtuais e alguns programas de voz. Mas como todos os recursos utilizados pela C.A., o computador também terá que estar adaptado a cada aluno como, por exemplo, o mouse ser no pé, o teclado ser maior para haver o toque. Importante destacar que, assim como em outros recursos, no computador também há o contato direto e a varredura automática pode ser acionada com um gesto, um sopro, um olhar etc.

O uso do computador como um instrumento de ensino é apontado por Bersch\&Schirmer (2005), o qual caracterizam, dizendo que,

\begin{abstract}
A indicação de um recurso de adaptação do computador, parte da avaliação do usuário e suas competências. A partir de então, vamos eleger alternativas que poderão ser, por exemplo, um simples ajuste nas "opções de acessibilidade" do computador (onde evitamos repetições de letras, aumentamos tamanho de fonte ou de cursor, promovemos aderência de teclas - favorecendo a digitação com uma só mão, utilizamos as teclas numéricas como alternativa para o mouse), até a indicação de um teclado especial (expandido ou reduzido) [...] (BERSCH \& SCHIRMER, 2005, p. 91).
\end{abstract}

Assim como Bersch\&Schirmer (2005) Johnson (1998) também falam sobre a importância que se tem de ter uma avaliação da pessoa por especialistas para ter o acesso a esses dispositivos de alta tecnologia.

Bersch\&Schirmer (2005) ainda destacam que para pessoas cegas, com baixa visão ou deficiente físico, existem programas por comando de voz ou até mesmo acionadores a partir da pressão, do sopro, piscar de olhos e entre outros.

Criar Educação, Criciúma, v. 6, n², julho/novembro 2017.- PPGE - UNESC 


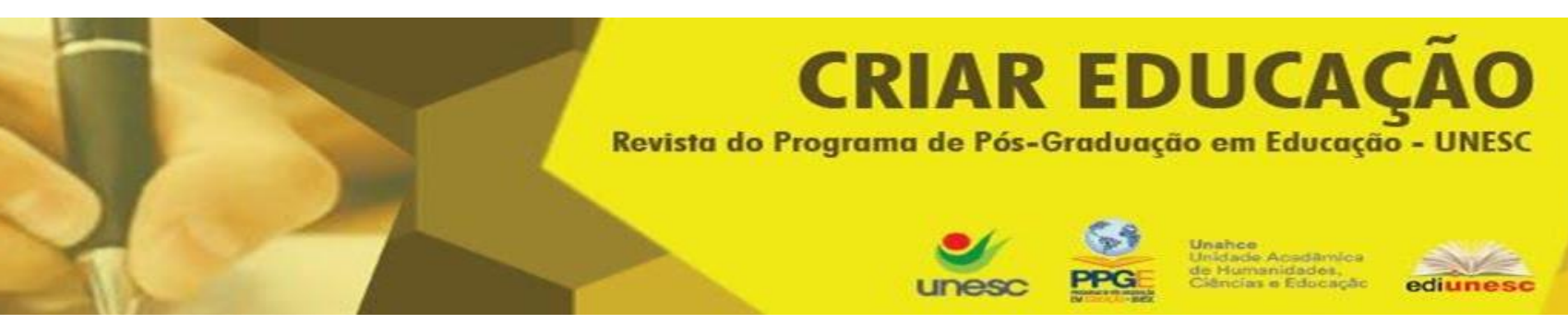

Os recursos de acessibilidade ao computador são divididos pelas autoras em grupos, como hardwares e softwares.

Como hardwares de TA encontramos a impressora braile, os teclados expandidos, bases sensíveis ao toque e ajustáveis à condição de coordenação motora do usuário, mouses diversos, acionadores etc. No grupo dos softwares de TA encontramos os teclados virtuais, mouses virtuais, programas com varredura visual ou auditiva, programas acionados com comando de voz, ou a partir da percepção de movimento de alguma parte do corpo do usuário, leitores de tela etc. (BERSCH \& SCHIRMER, 2005, p. 91).

Referente às tecnologias, Passerino (2010), traz a importância que essas têm no contexto, inseridas na vida, no dia-a-dia dos alunos e de todos. A autora nos mostra que a cada dia está havendo uma crescente interação das crianças com essas tecnologias e que isso deve ser aproveitado pela escola, buscando despertar no aluno a curiosidade de aprender, o pensamento, etc.

\footnotetext{
Usar as tecnologias como ferramentas do pensamento parte, portanto, de uma concepção de aprendizagem interacionista, na qual tanto aluno como professor, sujeitos ativos e aprendentes, entram em interação valendo-se de recursos e tecnologias para construir um espaço educativo que promova a aprendizagem ativa, construtiva, reflexiva, dialógica, intencional e contextualizada (PASSERINO, 2010, p. 11).
}

Para acontecer esta interação do professor com o aluno, o professor precisa saber usar a sua metodologia, saber usar a tecnologia. Nada adianta, a escola ter a tecnologia (ex: Computador) e o professor não saber usar. Assim, o professor precisa fazer formações continuadas que o capacite para poder interagir de forma mais eficiente com os seus alunos.

De acordo com Manzini \&Deliberato (2006), "o uso do material de comunicação possibilita maior interação com o professor, com os colegas da própria sala de aula e com os demais alunos da escola" (2006, p.39). Fazendo as

Criar Educação, Criciúma, v. 6, n², julho/novembro 2017.- PPGE - UNESC 


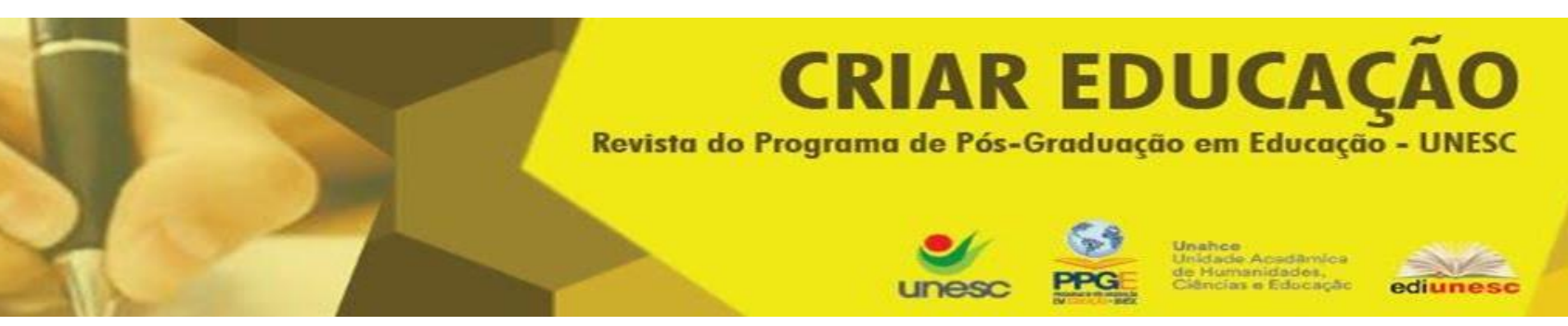

adequações necessárias, os alunos conseguem se inteirar das atividades em sala e poderão ter relações com seus colegas e professores.

\section{METODOLOGIA}

A pesquisa foi realizada em uma instituição de ensino do município de Laranjeiras do Sul após o consentimento e a autorização da direção para realizar a observação da relação/mediação do professor com o aluno deficiente e a utilização da C.A.Esta pesquisa foi realizada em torno da abordagem qualitativa, a qual é destacada por Lüdke (1986), que traz a apresentação de Bogdam e Biklen, onde falam que "pesquisa qualitativa tem o ambiente natural como sua fonte direta de dados e o pesquisador como seu principal instrumento" (LÜDKE, 1986, p. 11).

A observação teve como critério considerar alguns aspectos para análise conforme roteiro que segue: materiais de C.A.; materiais de alta e baixa tecnologia; cursos para a capacitação de professores referentes à C.A.; materiais confeccionados pelos professores;utilização da C.A. em casa pelos alunos; a C.A. está adequada ao contexto escolar; sequência de introdução: objetos concretos, miniaturas, fotografias, símbolos, letras e palavras;envolvimento dos pais; adaptação da comunicação para cada aluno; mediação do professor.

\section{RESULTADOS E DISCUSSÕES}

"De maneira brilhante, Vygotsky estendeu esse conceito de mediação na interação homem-ambiente pelo uso de instrumentos, ao uso de signos" (COLE, 1991, p. 11). Segundo Reily (2012), na educação especial é preciso garantir o

Criar Educação, Criciúma, v. 6, n², julho/novembro 2017.- PPGE - UNESC 


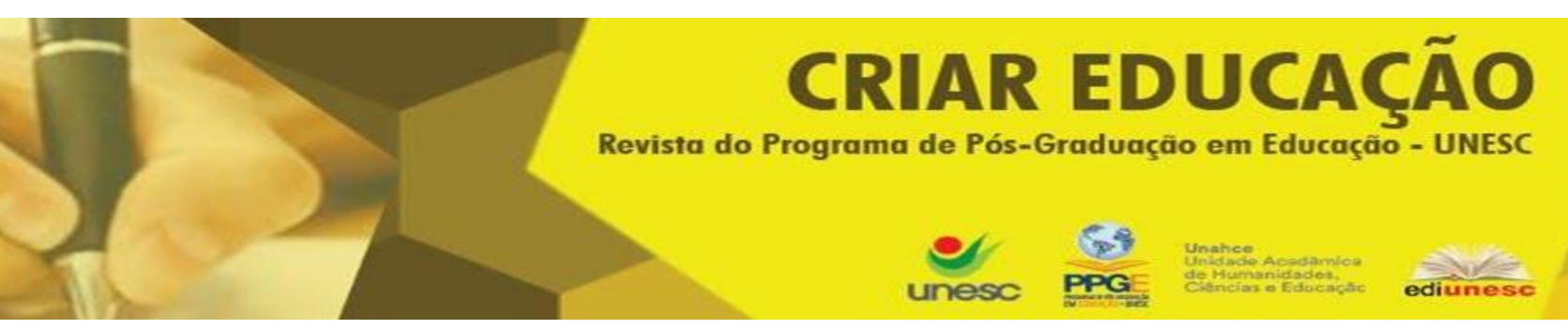

acesso por meio de instrumentos que sejam acessíveis ao deficiente, ou seja, de uma maneira que ele seja capaz de realizar.

Após passar por seis salas, escolhemos uma sala para observar, a qual, segundo a psicóloga, a professora utilizava muito a Comunicação Alternativa. Nesta sala há cinco alunos, um autista e quatro com Paralisia Cerebral. A professora foi muito receptiva, como em todas as outras. Com a observação nesta sala, foi possível termos mais a interação com a professora da turma, a partir de perguntas e conversas relacionadas às suas metodologias de trabalho com os alunos.

Assim, é com a Comunicação Alternativa que o professor poderá incluir o aluno deficiente, fazendo com que ele não seja passivo, mas sim ativo, que tenha oportunidades de se expressar com todos que o cercam.Desta forma, foi perguntado à professora como ela utilizava a Comunicação Alternativa na turma. A mesma mostrou materiais confeccionados por ela, como: calendários ilustrados (os dias de vir à escola eram representados por um lápis e o sábado e domingo por uma casinha, significando os dias que ficavam em casa). Com este material percebemos que "A mediação se dá com instrumentos sígnicos, quando, por exemplo, alguém se utiliza de anotações para lembrar o que precisa comprar no supermercado" (REILY, 2012, p.19). Pois, estes recursos metodológicos são um signo, que permitem fazer com que o aluno com necessidades especiais saiba os dias que está na escola e os dias que está em casa.

A atividade (FIGURA I) referente aos períodos do dia é realizada diariamente. O cartaz do tempo e dia/noite possibilita que a professora converse com os alunos, questionando-os sobre como o dia se encontra, se está dia ou noite, se o dia está ensolarado ou chuvoso. Nesta atividade, a professora aproveitava para perguntar como foi o final de semana em casa, como estava o tempo, se estava chovendo e o que era preciso usar quando sair de casa (Guarda-chuva). Também questionava sobre quando tem sol, se precisa ou não usar protetor solar.

Criar Educação, Criciúma, v. 6, n², julho/novembro 2017.- PPGE - UNESC 

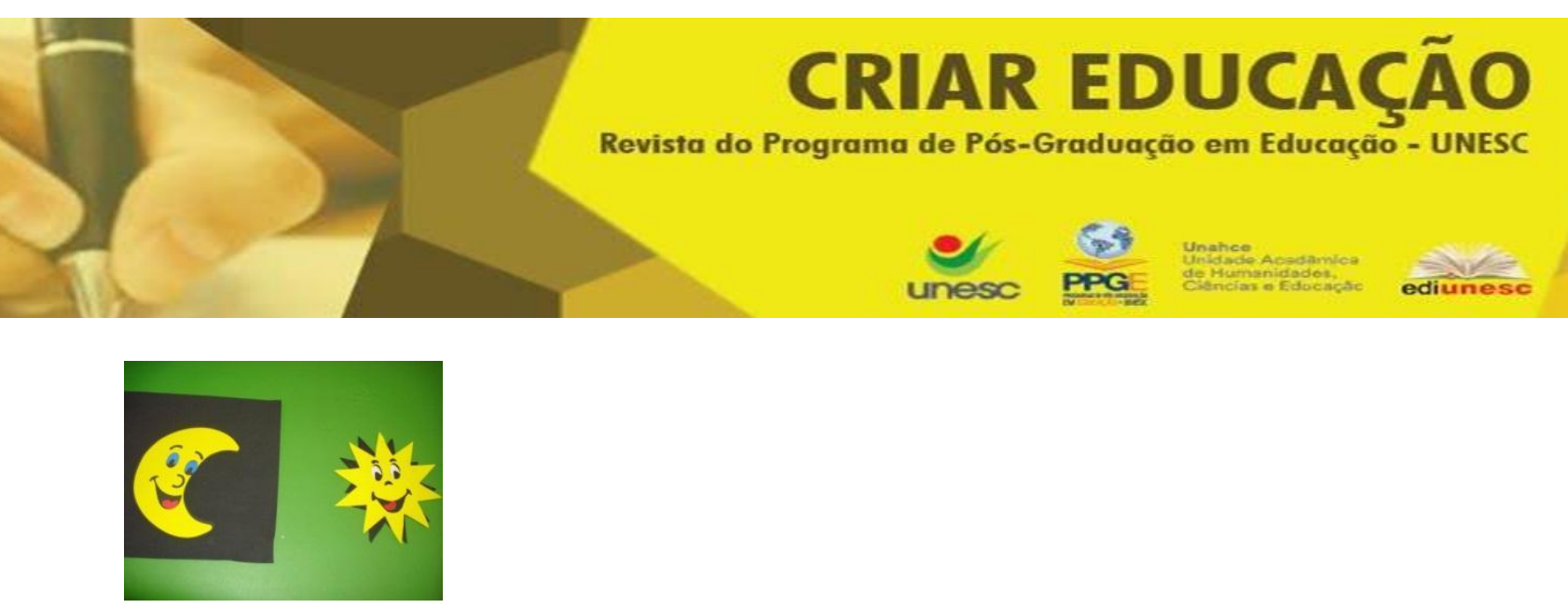

FIGURAI - Tempo (Confecção de Sandra Pereira Rohr) Fonte - Ana Paula Burei

Ao mostrar os materiais, a professora relatou que faz toda uma conversa para falar sobre as datas, o tempo, pois disse que às vezes ela fala sozinha, mas sabe que eles entendem e às vezes surge algum som, um piscar de olhos, mas deve sempre estar muito atenta para observar a reação de cada um. Quando perguntada se utilizava as pranchas de comunicação, falou que não usa as pranchas prontas, pois acha ruim de trabalhar, disse que é sem vida, sem sentido, não chama a atenção, isso para ela, portanto, prefere confeccionar seus próprios materiais. Gosta de trabalhar com fichas, avental, cartazes contendo figuras bem coloridas, tudo confeccionado por ela. Para exemplificar, ela mostrou fichas tema era comida (feijão cru, cozido, feijoada, milho, fubá, polenta, frutas). (FIGURA II)

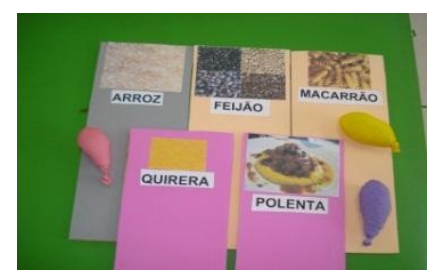

FIGURAll - Fichas de comida (Confecção de Sandra Pereira Rohr - Fonte Ana Paula Burei)

Para realizar uma atividade com essas fichas, ela tem dentro de um balão sementes de feijão, arroz milho, etc. Assim, não se fica apenas em uma ficha, mas é feita toda uma conversa, vai além, fazendo com que o aluno perceba a diferença dos grãos. Também explicou que quando trabalha com comida e não tem dentro do balão, procura trazer o alimento cru para mostrar, como os formatos de macarrão.

Criar Educação, Criciúma, v. 6, n², julho/novembro 2017.- PPGE - UNESC 


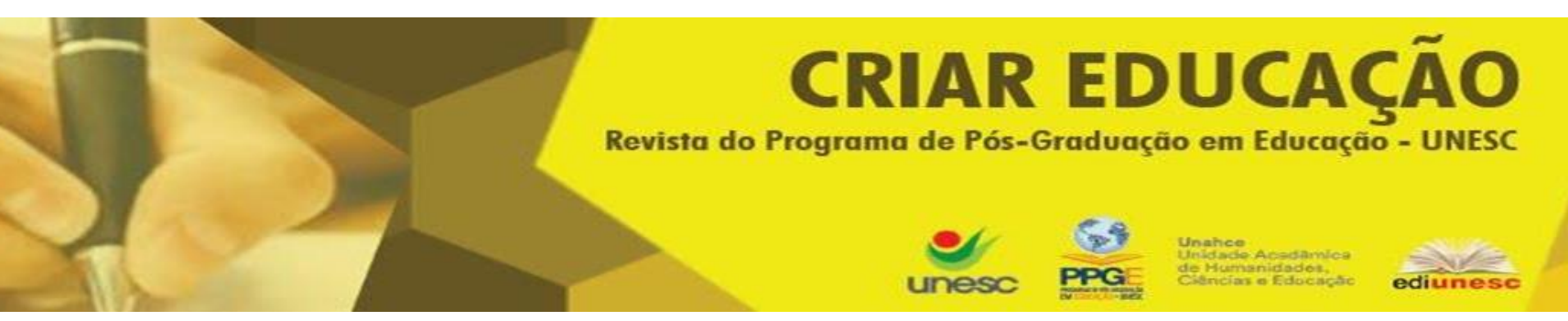

Com a atividade, a professora vai mostrando o que vai ter de lanche no dia, por exemplo, a polenta, ela pergunta ao aluno: você gosta de polenta? Assim, colocando o balão na mão para que a criança sinta o milho. Dessa forma, ao fazer as perguntas, coloca na carteira ficha com carinhas e as respostas "sim" e "não", esta na cor vermelha e a outra verde, (FIGURA III) Diante desse material, os alunos são incitados a, com uma parte do corpo, indicar seu gosto. Ou ainda, a resposta pode vir por meio do sistema de varredura, onde ela mesma faz a indicação nas placas, esperando um sinal do aluno, como um sorriso, um piscar de olhos ou até um resmungo.

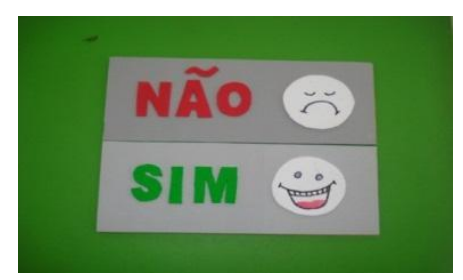

FIGURAIll - Sim/Não (Confecção de Sandra Pereira Rohr - Fonte Ana Paula Burei)

Ao trabalhar com a comida, a professora aproveita para trabalhar com os utensílios que são utilizados para a alimentação. Durante essa atividade (FIGURA IV), a professora vale-se de figuras que são colocadas para os alunos para que estes possam responder o que é necessário para se comer polenta, por exemplo, "Será que precisamos de uma colher? De um prato? E para tomar suco, o que precisamos? E quando sujamos a boca devemos limpá-la com o quê?

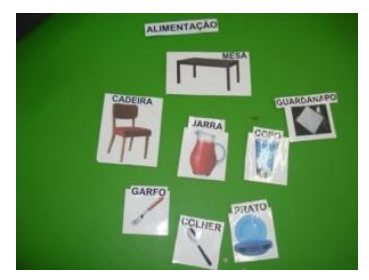

FIGURA IV - Utensílios (Confecção de Sandra Pereira Rohr - Fonte Ana Paula Burei)

Criar Educação, Criciúma, v. 6, o2, julho/novembro 2017.- PPGE - UNESC 


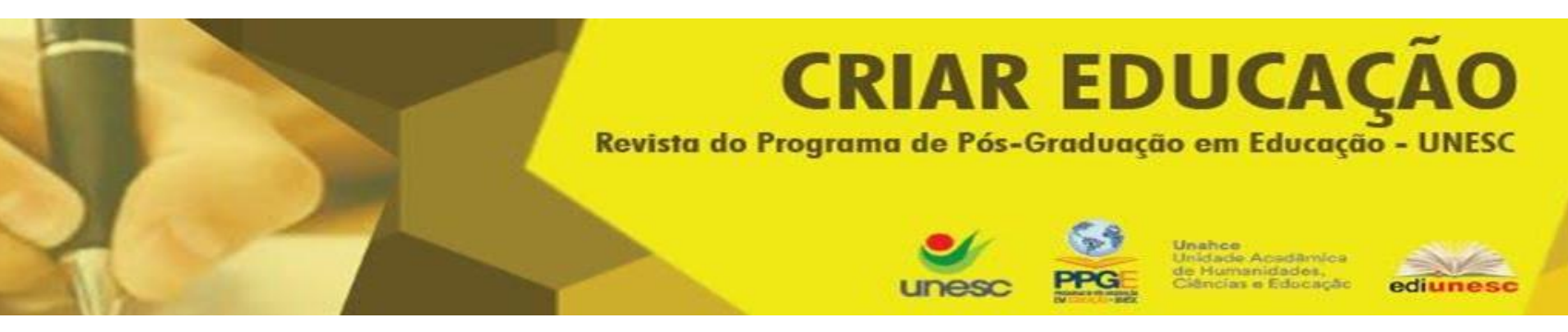

Outro ponto muito importante sobre as pranchas e as fichas é o seu tamanho, na prancha é um tamanho pequeno. Já nas fichas pode-se fazer um tamanho grande que chame a atenção. Em relação a chamar atenção dos alunos, a professora mostrou uma atividade que tinha feito com eles sobre o boné, na qual realizou toda uma introdução, mostrando-o tamanhos grande e pequeno. Os alunos entendiam, então foi proposta uma atividade no papel em que eles tinham que indicar o boné grande e o pequeno, no entanto, eles não acertavam, pois aquele papel não fazia sentido para eles.

O trabalho com as frutas (FIGURA V), buscando o lado real das coisas, o tamanho, figuras coloridas que chamam a atenção. Mas para ser trabalhado com essas frutas no papel, é preciso primeiro trazer as frutas reais para, em seguida, trazer as miniaturas idênticas, para, só aí passar para o papel.

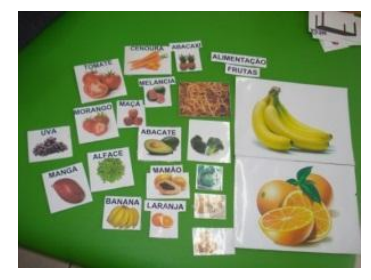

FIGURA V - Frutas (Confecção de Sandra Pereira Rohr - Fonte Ana Paula Burei)

Assim, a introdução a Comunicação Alternativa deve ser feita aos poucos, a partir da realidade do aluno, de objetos, fotos da família, para em seguida ir para o papel.

Em relação ao tamanho das figuras, das pranchas, das fichas, a professora mostrou uma atividade de montar que deve ser adaptada às dificuldades do aluno (FIGURA VI). A atividade consiste em montar o rosto, utilizando expressões faciais sendo que o aluno tem várias possibilidades de montagem, desde o cabelo, os olhos, até um sorriso. Mas esta atividade tem muitas expressões, por isso é aconselhável se trabalhar uma expressão por vez, como por exemplo: um dia trabalhar a expressão da boca, outro dia dos olhos e assim por diante.

Criar Educação, Criciúma, v. 6, nº2, julho/novembro 2017.- PPGE - UNESC 

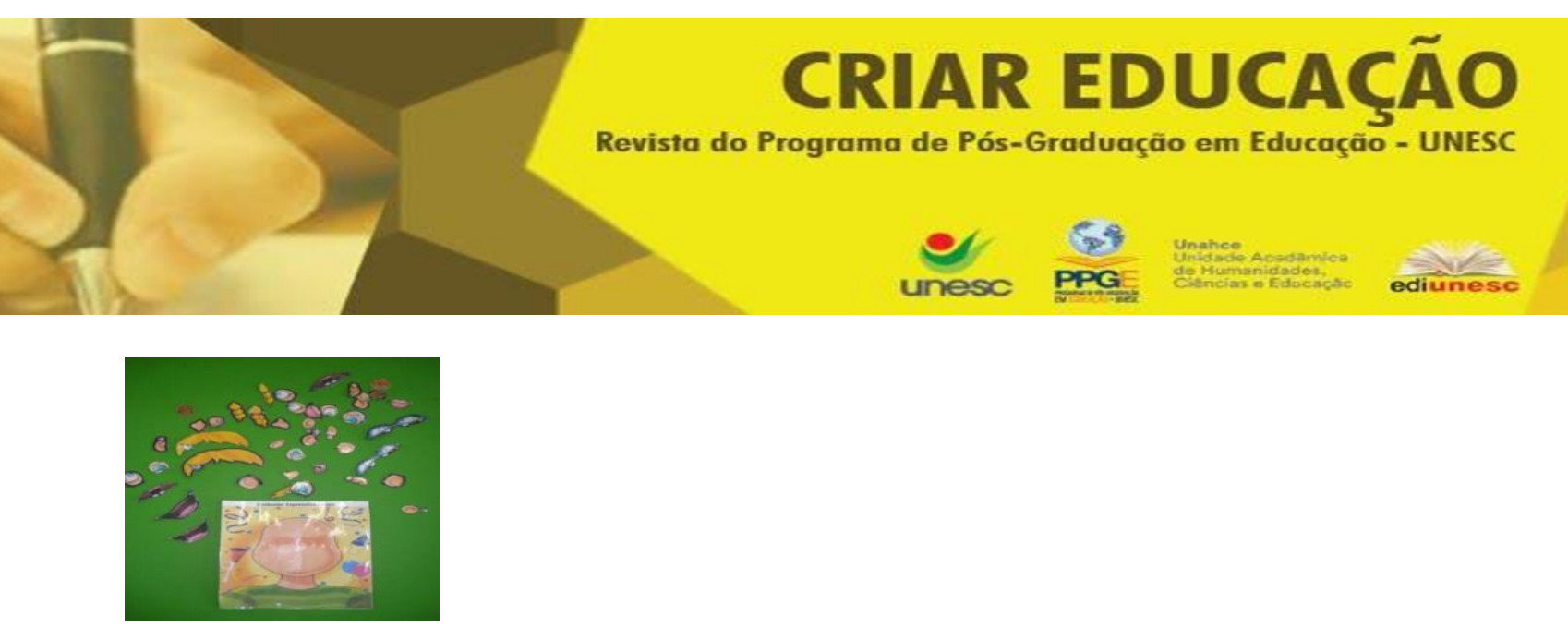

FIGURA VI - Expressão facial (Confecção de Sandra Pereira Rohr - Fonte Ana Paula Burei)

Assim, é muito importante conhecer cada aluno e procurar planejar as atividades pensando em cada um, em suas potencialidades. Vale destacar que o trabalho individual permite que todos participem das atividades e, dessa forma, "O professor que atua de uma perspectiva mediadora na sala de aula também se transforma no decorrer do processo de ensino" (REILY, 2012, p.19), pois, está dando oportunidades para o aluno se desenvolver, mostrando caminhos para o professor desenvolver o processo de ensino-aprendizagem.

Para trabalhar com o corpo, a professora utiliza prancha de comunicação, a qual coloca para o aluno e, ao seu lado, espalha várias figuras das partes do corpo (orelha, olhos, perna, braço, etc.) (FIGURA VII). Diante disso, surgem, questionamentos, como "o que eu faço com as minhas unhas? E o meu cabelo, deixo crescer ou corto? O que faço para ficar limpinho?". E assim, ele tem que colocar as figuras correspondentes nas pranchas. Também pode iniciar pela prancha, mostrando um membro do corpo por vez. Desta forma, mostra e pergunta: “onde está o braço,vamos encontrá-lo?, e as mãos?".

Criar Educação, Criciúma, v. 6, n², julho/novembro 2017.- PPGE - UNESC 

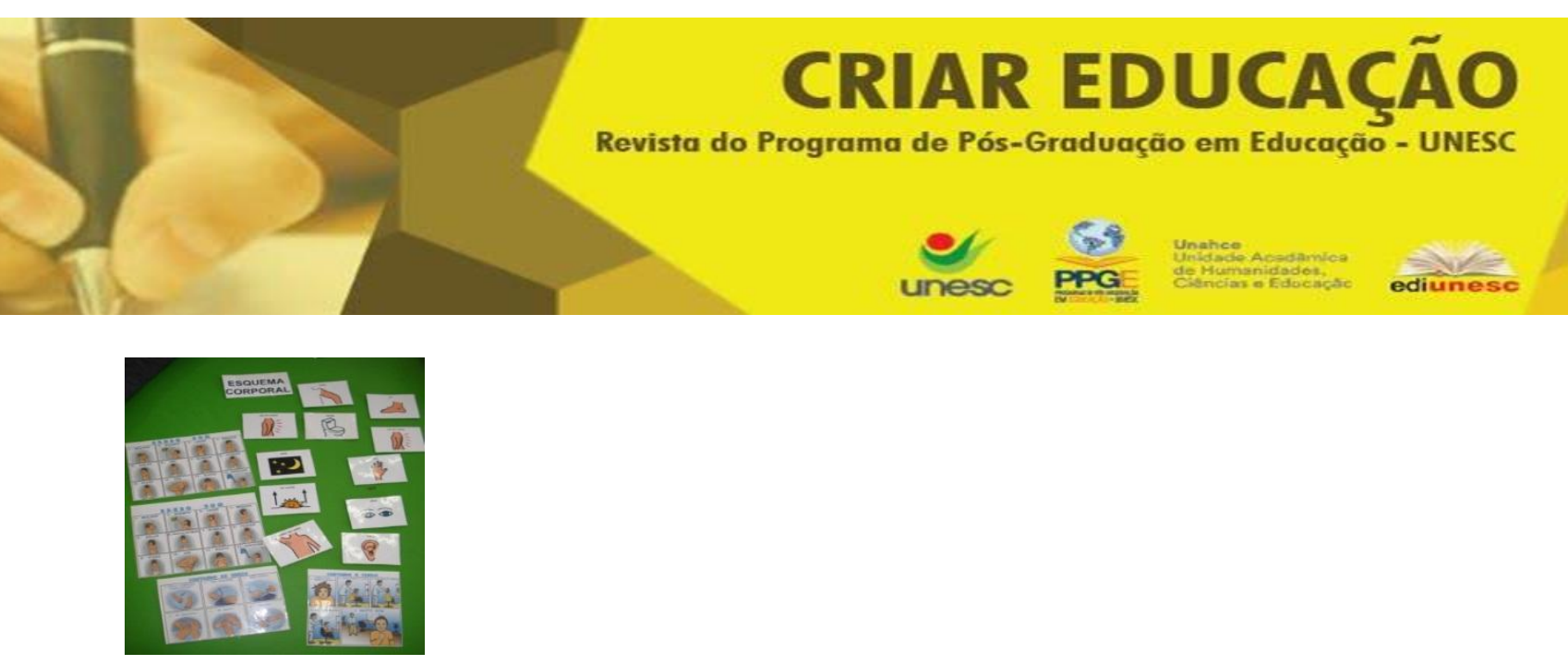

FIGURA VII - Membros do corpo (Confecção de Sandra Pereira Rohr - Fonte Ana Paula Burei)

Aproveitando o trabalho com o corpo, pode ser trabalhada a higiene pessoal (FIGURA VIII) da mesma maneira que a expressão corporal, fazendo perguntas a eles, como: "o que precisamos para escovar os dentes? $\mathrm{E}$ para tomar o banho?". Assim, vai sendo colocado ou apontado nas pranchas. Essa figura mostra uma prancha com feltro colado, onde os alunos podem grudar figuras.

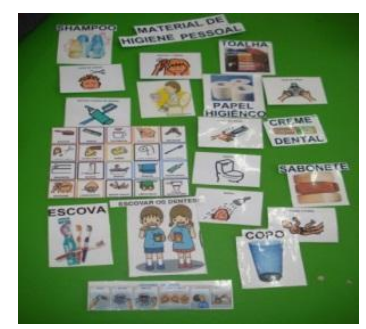

FIGURA VIII - Higiene corporal (Confecção de Sandra Pereira Rohr - Fonte Ana Paula Burei)

O trabalho com as cores, segundo a professora, deve ser feito usandose apenas uma cor de cada vez (FIGURA IX). Um exemplo de atividade nessa perspectiva seria escolher uma cor por semana, como o amarelo, o que faria com que o planejamento se voltasse para objetos que fossem dessa tonalidade. Por sua vez, o trabalho com duas cores é mais complicado, pois eles têm que dominar a cor, assim, é aconselhável que no início seja apenas uma cor. Assim, a prancha pode ser exposta na parede, para que a cada semana seja grudada mais uma cor aprendida.

Criar Educação, Criciúma, v. 6, nº2, julho/novembro 2017.- PPGE - UNESC 

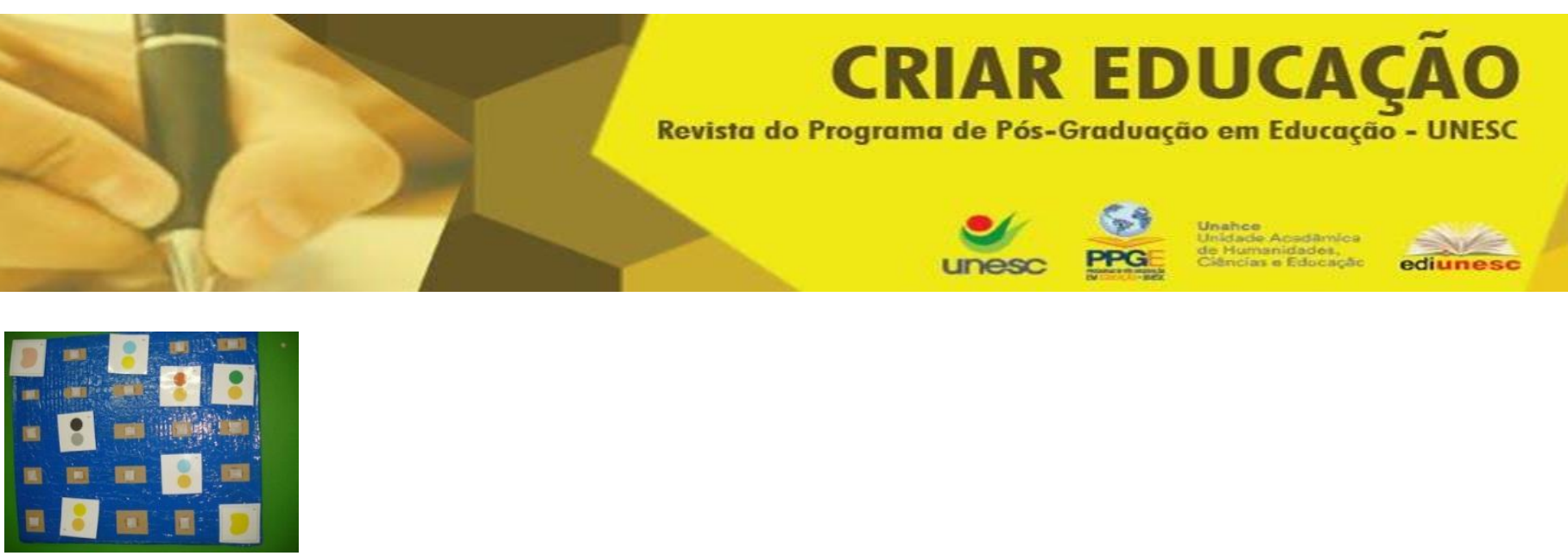

FIGURA IX - - Cores (Confecção de Sandra Pereira Rohr - Fonte Ana Paula Burei)

Outra atividade que se pode fazer é a atividade de localização (FIGURA X), na qual são colocadas para o aluno figuras como a casa, o ônibus, o sol e a nuvem. A professora vai questionando: "onde você estava antes de vir à escola? Quando você saiu de casa você veio do que para a escola? Está chovendo?". Assim, pode incluir brinquedo, figuras de banho, de comida, para perguntar o que ele fez em casa antes de vir à escola, etc.

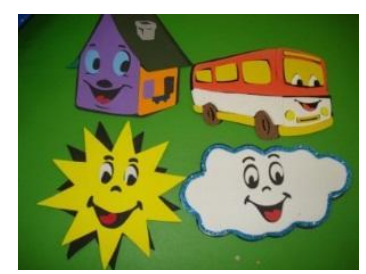

FIGURA X - Localização (Confecção de Sandra Pereira Rohr)

O que chamou muita atenção é que a professora falou que em casa não há essa comunicação, inúmeras vezes porque os pais não conhecem, não vão atrás ou até mesmo por cômodo.

Foi perguntado à professora se a APAE realiza encontros para tratar da Comunicação Alternativa e ela falou que não, nunca aconteceu isso, e que ela buscava os materiais por si só, sempre na internet, atividades que quase sempre teve que adaptar. Busca ler artigos que falam sobre o assunto, mas salientou que os textos e os livros são muito bons para o conhecimento, mas que na vida real, na prática, muitas vezes não dão certo, é preciso adaptar a sua realidade. Afirma,

Criar Educação, Criciúma, v. 6, ํ2, julho/novembro 2017.- PPGE - UNESC 


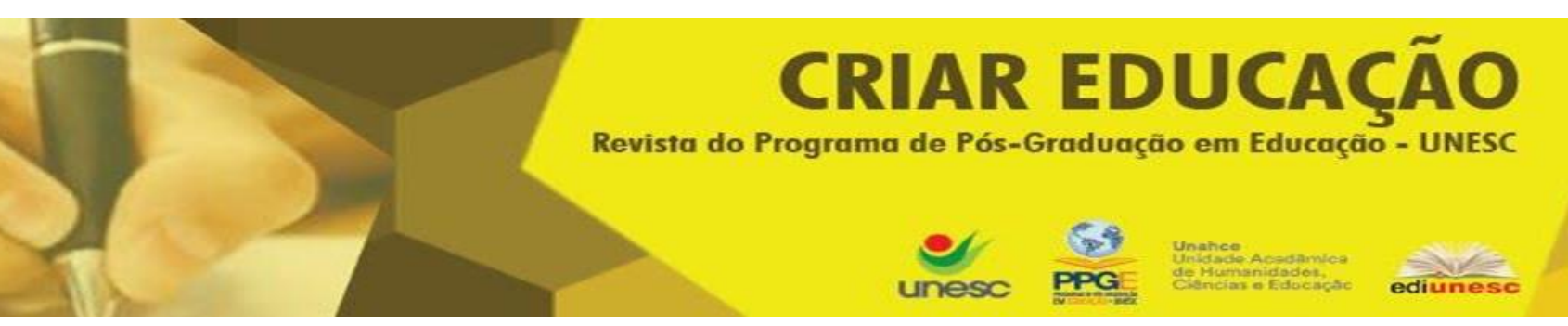

ainda, que muitas coisas que estão na teoria não acontecem ou não dão certo na prática, mas é lógico que a teoria dá muito base.

Mesmo não tendo cursos que a capacite, a respeito da C.A., pelo o que percebemos na observação, a professora utiliza lança mão de materiais de C.A. Não usa as fichas/placas de comunicação prontas, pois verificou-se que estas não surgem efeito, por serem sem cor, não sendo, portanto atrativas para as crianças. Também faz a introdução da metodologia, conforme estudamos, iniciando por objetos reais, depois com miniaturas, fotos, figuras e palavras.

\section{CONSIDERAÇÕES}

O presente trabalho teve origem na curiosidade de se compreender como o professor trabalha em sala de aula, para possibilitar aos sujeitos a construção de seus conhecimentos. Com isso, buscamos responder nossa pergunta: A prática do professor utiliza a Comunicação Alternativa como uma metodologia, contribuindo na aprendizagem do aluno? Com essa pergunta, tínhamos um objetivo que era o de compreender a Comunicação Alternativa com suas contribuições para a interação de professor e aluno deficiente físico.

Após fazer várias leituras a respeito da C.A., fomos a campo, para fazer análise de dados, por meio da observação, buscando fazer um paralelo da realidade observada, com a teoria estudada. Com esta análise, pudemos verificar que a escola possui poucos materiais de C.A., e todos os anos os professores confeccionam materiais, mas não deixam na escola.

$\mathrm{Na}$ observação, percebemos que os professores utilizam a C.A., tentam fazer o possível, estudam por conta própria, buscando materiais para adaptar, a fim de trazer para sua turma, sempre fazendo paralelo com a realidade. A

Criar Educação, Criciúma, v. 6, nº2, julho/novembro 2017.- PPGE - UNESC 


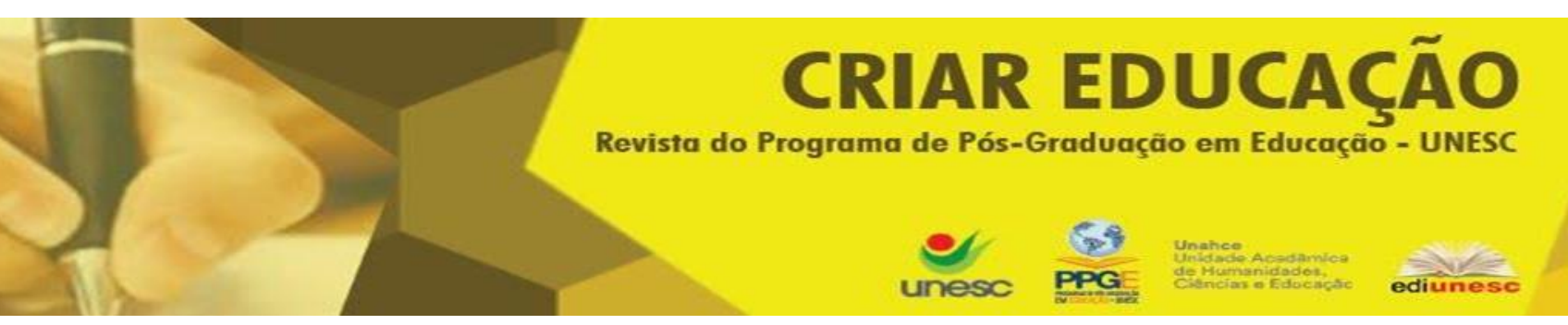

introdução da C.A é feita a partir objetos parecidos com o real, para depois ir par as fotos, figuras e depois palavras, para assim, ter uma introdução que seja válida.

Consideramos que o estudo teve grande importância, pois foi possível conhecer a C.A e reconhecê-la na escola, na prática dos professores. Percebemos que por ser um assunto muito novo na área da Educação Especial, a C.A. ainda está engatinhando. Mas para que esta ande, precisa ser trabalhada desde a graduação, precisa ter investimentos e qualificação do professor.

\section{REFERÊNCIAS}

AVILA, Barbara Gorziza, et al. Usabilidade em tecnologia assistiva: estudo de caso num sistema de comunicação alternativa para crianças com autismo. Revista Latinoamericana de Tecnologia Educativa. v.12. Porto Alegre, 2013.

BERSCH, Rita; SCHIRMER, Carolina R. Tecnologia Assistiva no Processo Educacional. In: BLANCO, Rosa, et al.Ensaios Pedagógicos: Construindo Escolas Inclusivas. Brasília: MEC/SEESP, 2005.

BERSCH, Rita. Tecnologia Assistiva - TA. In: SCHIRMER, Carolina R., et al. Atendimento Educacional Especializado: Deficiência Física. São Paulo: MEC/SEESP, 2007.

BERSCH, Rita; SCHIRMER, Carolina R. Comunicação Aumentativa e Alternativa CAA. In: SCHIRMER, Carolina R., et al. Atendimento Educacional Especializado: Deficiência Física. São Paulo: MEC/SEESP, 2007.

COLE, Michael (Org.) et al, A formação social da mente: VYGOTSKI, L. S. 4. Ed. São Paulo - SP:Livraria Martins Fontes, 1991.

JOHNSON, Roxanna. Guia de Símbolos de Comunicação Pictórica. Porto Alegre: Clik, 1998.

Criar Educação, Criciúma, v. 6, ำ2, julho/novembro 2017.- PPGE - UNESC 


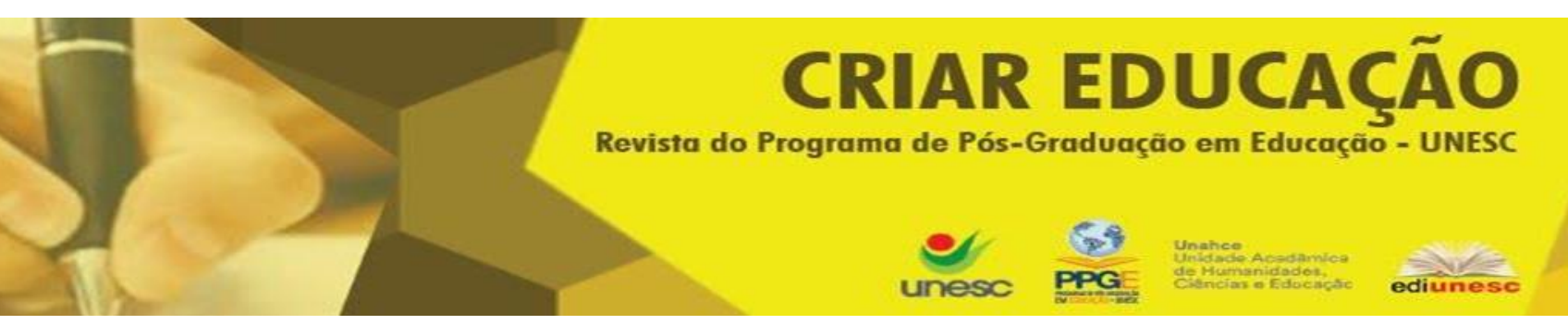

LÜDKE, Menga. Abordagens qualitativas de pesquisa: a pesquisa etnográfica e o estudo de caso. In: Pesquisa em educação: abordagens qualitativas. São Paulo: EPU, 1986.

MANZINI, Eduardo José. Tecnologia Assistiva para a educação: recursos pedagógicos adaptados. In: BLANCO, Rosa, et al.Ensaios Pedagógicos: Construindo Escolas Inclusivas. Brasília: MEC/SEESP, 2005.

MANZINI, Eduardo José; DELIBERATO, Débora. Portal de ajudas técnicas para educação : equipamento e material pedagógico especial para educação, capacitação e recreação da pessoa com deficiência física : recursos para comunicação alternativa. 2. ed. Brasília : MEC/SEESP, 2006.

OLIVEIRA, Marta Kohl. Vygotsky. Aprendizado e Desenvolvimento. Um processo sócio-histórico. São Paulo: Scipione, 1993.

PARANÁ. M I N U T A INSTRUÇÃO № / 2011 - SUED/SEED

http://www.educacao.pr.gov.br/arquivos/File/Consultas/minuta instrucao.pdf

Acesso em: 23 de agosto de 2015

PASSERINO, Liliana. Apontamentos para uma reflexão sobre a função social das tecnologias no processo educativo. (Universidade Federal do Rio Grande do Sul), 2010.

REILY, Lucia. Fundamentos e Pressupostos: Cultura, linguagem, mediação, ensino e aprendizagem. In: REILY, Lucia. Escola Inclusiva: Linguagem e mediação. 4. ed. Campinas - SP: Editora Papirus, 2012.

RIBAS, João B. Cintra. 0 que são pessoas deficientes. 6. ed. São Paulo: Brasiliense, 1994.

Criar Educação, Criciúma, v. 6, no2, julho/novembro 2017.- PPGE - UNESC 